\title{
State of the Population Disclosure Systems in the Changing Radiation Situation in Bulgaria
}

\author{
Dolchinkov Nikolay Todorov \\ „,Vasil Levski“"National Military Univer- \\ sity, Veliko Tarnovo, Bulgaria \\ National Research University "Moscow \\ Power Engineering Institute”, Moscow, \\ Russia \\ Veliko Tarnovo, Bulgaria \\ n_dolchinkov@abv.bg \\ ORCID: 0000-0002-6171-6083
}

\begin{abstract}
In February and March 2017, I conducted a survey among 3 population groups and 392 participants on the state of the population monitoring and disclosure systems so that the information received was up to date. The resulting and aggregated information should not be considered as a constant because the situation changes dynamically, both in terms of the political situation in the region and the intentions of our neighbours regarding the sites that represent both the radiation risk and the meteorological elements that affect any radioactive contamination. Especially dynamic is the development of meteorological elements, which should be analyzed very thoroughly in the event of a nuclear accident or incident. The results of the study are presented, diagrams and analyzes and guidelines for follow-up are presented..
\end{abstract}

Keywords - danger, disclosure systems, population, radioactive background

\section{INTRODUCTION}

The topic of radiation safety is very painful for society. Despite its timeliness, its relevance has not diminished over the past 30 years. In order to increase the monitoring of the radioactive situation, the nuclear accidents in Chernobyl in 1986 and in Fukushima in 2011 played a major role. Simultaneously with the use of the atom for peaceful purposes, over the past 2 years, there has been an increase in the development of new and advanced nuclear weapons. Even in recent months, there has been intense talk about ending the operation of the Nuclear Weapons Convention by leading world powers $[1,5,8]$.

Bulgaria is at the forefront of Europe, Asia and Africa where people, technology, weapons, and smuggling are being deployed. This, along with the increased terrorist activity in Europe and the banging of weapons around Bulgaria leads to a concern in part of society [2]. We can not be indifferent to what kind of world we live in and what happens around us.

All of this has led me to make a survey of the population to what extent it is aware of the problems of radiation safety and what each of us should do in the event of a radiation accident in Bulgaria or near Bulgaria which will lead to an increase of the natural radioactive background [9]. The extent to which the public is aware of the procedures and actions to be taken in changing the radioactive situation should be increased. As a purpose, I set myself to explore the real state of public awareness and analyzing information to identify awareness-raising measures. I segmented the community to get more reliable information to summarize and analyze. In order to achieve the purpose I set up a questionnaire with specific questions and I made a preliminary study of the problem [5].

\section{MATERIALS AND METHODS}

In Bulgaria, such a survey has not been done over the past 15 years, and there is no evidence of such a study being made before. After a year's familiarization with the state of the problem, the structure of the organizations in the direction and the current legislation in Bulgaria and the European Union formulated the main directions of the future study. Based on the studies, aggregation of information and analysis of the results, I made a questionnaire containing 20 questions, which represented the problem in a wide range. $[8,10]$. The inquiry included issues that covered the overall vision of radiative background monitoring systems, population disclosure, action by competent authorities and bodies and their interaction. Together with these basic radiation protection values, the respondents also expressed their opinion on the main factors that could lead to a radiation accident and the manner of distribution of the radioactive particles, isotopes and rays in terms of the meteorological elements that influence them. The volume of survey questions was chosen so that it could fully cover the research problem from all the relevant points of view, and in the same time, not being boring for the survey participants. With the number of questions raised, there is a danger that respondents will not pay enough attention to the issues raised and those who I am at the end of the poll will not give a credible answer. That's why 20 questions were selected for the survey $[3,7]$. If it goes to the other extreme and there are too few questions, then we will not get the amount of information we need for the scientific 
analysis of the problem and its subsequent findings.

The survey was conducted in February and March 2017 so that the information received is current at the time [8]. The resulting and aggregated information should not be considered as a constant because the situation changes dynamically, both in terms of the political situation in the region and the intentions of our neighbours regarding the sites that represent both the radiation risk and the meteorological elements that affect any radioactive contamination. Especially dynamic is the development of the meteorological elements and most of the wind, which should be analyzed very thoroughly in the event of a nuclear accident or incident.

\section{RESUlTS AND DISCUSSION}

To obtain an objective picture of the survey, the respondents were divided into three large groups. The first group consisted of radiation protection and nuclear physics specialists, who have a deeper understanding of the problems, and their opinion has a greater weight. Due to the specificity of the problem, people from different institutions working in this or near area were involved, but considering the research problem, their circle was not large - 38 people responded to the survey. In the selection of these specialists, I endeavoured to cover a wider range of institutions - Kozloduy NPP, BAS, MI, POHD, RIA to BAS and others, but due to the specificity of the problem, the circle of institutions was small. Due to the avoidance of subjective opinion, in the survey did not participate employees working in or being close to "Vassil Levski" National Military University.

The second group included randomly selected people from different age groups, educational qualifications, gender and religion from the whole country, randomly selected. In this category, the questionnaire was answered by 196 people.

I also made a study among the trainee students in the first course at the "Vasil Levski" Military University and the results were also processed and analyzed independently. Here were 158 students who had received initial training in nuclear, chemical and biological protection, and had some basic knowledge of nuclear accidents and their actions.

In summarizing the results, the views of the three categories of people are considered separately, making only a comparison, but not a general presentation of the problem, because these issues are specific and some knowledge in the field of radiation protection is needed in order to be able to respond competently. For some of the questions that do not require in-depth knowledge, the results are close, but where more knowledge is needed, there is already a greater difference in responses.

After the survey was completed among all learning categories, the results obtained were processed by me and summarized in tabular form. Based on aggregated data, we can make several statements.

1. According to the results of the study, the state of radiation protection in Bulgaria has gaps and the experts give a higher assessment of reality than the other 2 groups.

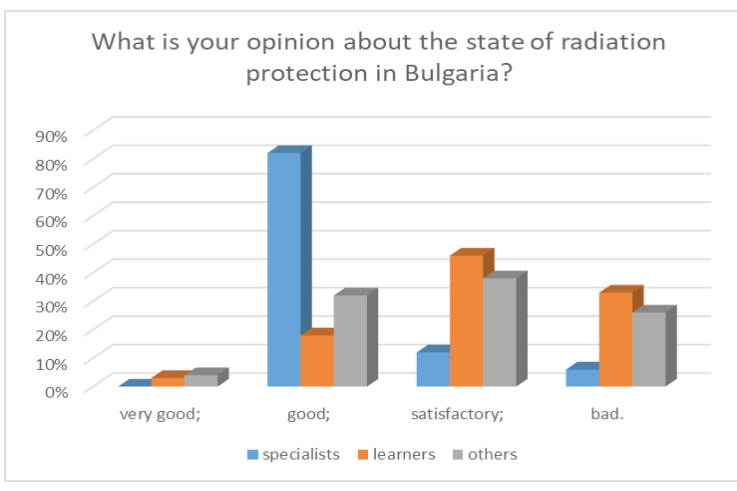

Fig. 1. Answer a question „What is your opinion about the state of radiation protection in Bulgaria?"“

The group of learners and people, selected randomly, gives a lower score, as the lack of information influences this. People with higher education also give higher marks than people with secondary and lower education (Figure 1).

2. The population at all is not aware of the measures, that need to be taken by the competent state, municipal and voluntary bodies in the event of a radiological emergency. This potential problem is seen with great disregard and disinterest by the majority of the population, regardless of gender, age, ethnicity, education. Such an event is seen as something unrealistic, fictitious, and as impossible happen in Bulgaria. Older people are more concerned about the problem than young people [5]. In responding, respondents with a higher level of education are more interested in the affected aspects of everyday life and are at least partially aware of the problems related to radiation protection, while those with secondary and lower education are ignorant and uninterested in the discussion in the consultation. Hence, the fact that the majority of respondents are not satisfied with the state policy, regarding the actions and measures taken in case of a radiation accident (Figure 2).

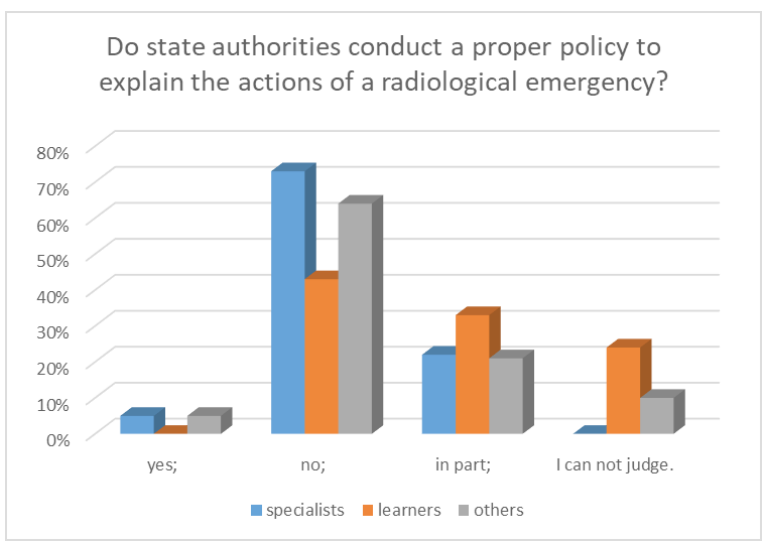

Fig. 2. Answer a question, „Do state authorities conduct a proper policy to explain the actions of a radiological emergency?"

3. In general, it can be made a report that people do not know the National Automated System for Continuous Control of the Background Radiation Range. The far more professional than the problem an interviewee is, 
the smaller his knowledge is . The same can be said of the educational level of the participants - people with higher education have a better idea of the system. In terms of gender, religion and age, the distribution is even and no response can be drawn. People who do not express an opinion are below $10 \%$ and are equally distributed among the different groups (Figure 3). In the consultation, a comment was often made that it is not my direct duties and I do not care.

The percentage of people familiar with the systems varied between $2 \%$ and $26 \%$, which is a very low percentage. On this basis, a high percentage of people who have responded positively to the effectiveness of these systems can not be expected. More than half can not assess the degree of coordination between organizations that monitor the radiation situation and manage the activity of managing a situation with increased radioactive background and take measures to reduce and limit the negative impact on people and the environment.

Do you know the National Automated System for Continuous Radiation Background Control (NASCRBC)?

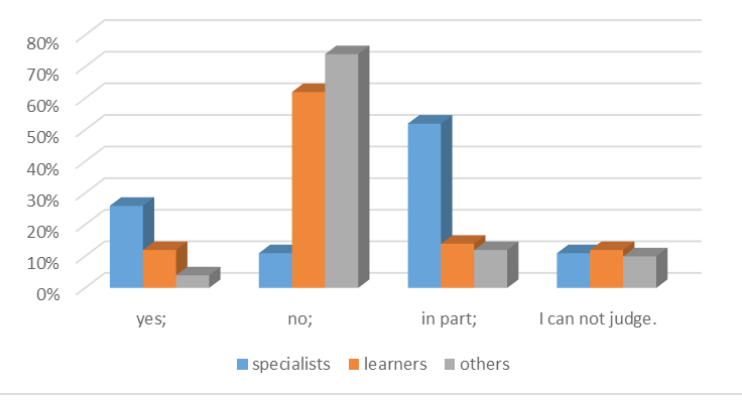

Fig. 3. Answer a question „Do you know the National Automated System for Continuous Radiation Background Control (NASCRBC)?“

Do you think it is necessary to do more and more qualitative exercises for changing the radiation situation?

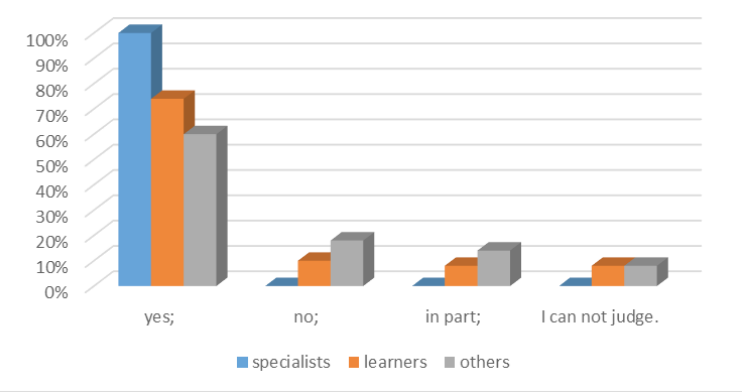

Fig. 4. Answer a question „Do you think it is necessary to do more and more qualitative exercises for changing the radiation situation?"

4. There is a concentration of responses to the need to conduct regular and up-to-date exercises for changing the radiation situation. Although much of the teachings are pre-directed, it is necessary to run regularly. An example here may be the teachings of Kozloduy NPP and other enterprises $[5,8]$. Good examples can also be taken from other countries with well-established structures such as Russia, France, Japan and others. It is a good impression that such exercises take place in some schools such as Emilian Stanev Secondary School, University of Sofia, „Professor Assen Zlatarov" Professional Lenguage School in Veliko Tarnovo and others. In conducting such exercises the respondents expressed the wish to participate more experts from the control bodies (Figure 4).

5. To a large extent, respondents have expressed the view that it is necessary for people who are professionally engaged in this to periodically increase their qualifications and to monitor changes in the field of radiation protection. It is necessary to issue documents with a fixed term to the workers, after which they have to undergo refresher training. This will maintain a higher level of competence for those working in the field. Here the answers are unambiguous and it is necessary to legislate the requirements. There is no deviation from any group in this question and the answers can be summarized for all respondents at all.

6. The sum of responses to the issues of coordination of the responsible authorities and agencies gives us a real picture of the population's interest in the real radiation situation, how it is monitored and what actions should be taken to reduce the negative impact. In this respect, the competent state authorities must necessarily improve their work among the population and their coordination among themselves. Only in this way would they weigh in their place, raise their authority, and the population would have greater faith in their actions.
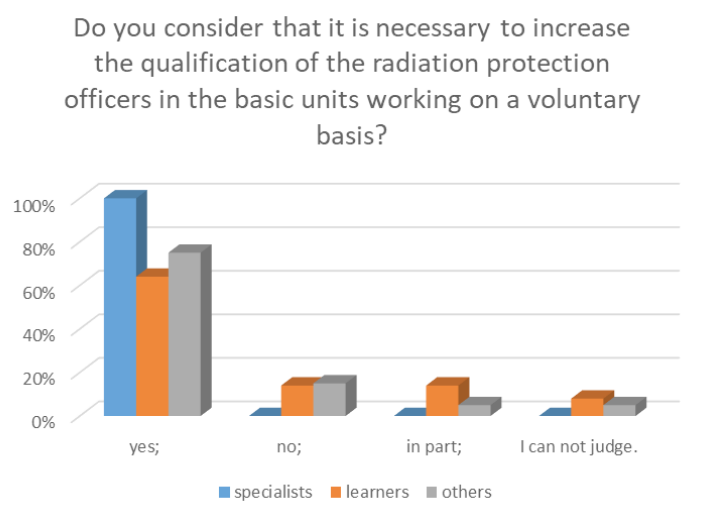

Fig. 5. Answer a question, ,Do you consider that it is necessary to increase the qualification of the radiation protection officers in the basic units working on a voluntary basis?“"

Here, also, the predominant is „I can not judge“ again, which is indicative of the fact that a large part of even the experts can not judge the real picture of the state of coordination among the most important authorities in the field of radiation protection. It is imperative for these important units for the state to become professionals and not leading to a continuous changing of structures and performers, depending on the political situation. For example, Italy may be given a position where, despite frequent political changes and elections, the Secretary of the Ministry of Foreign Affairs has headed for more than 30 years, and this creates the security of the institution he represents.

Figure 6 shows the assessment of the coordination 
between the responsible radiation monitoring institutions, according to the respondents.

All the inquiries about the need of more and better quality exercises and annual training of the staff responsible for monitoring the radiological situation and especially for government, local authorities and other non-governmental or voluntary organizations are all categorical.

Is there sufficient coordination between the departments that disclose the population in case of a radiation accident?

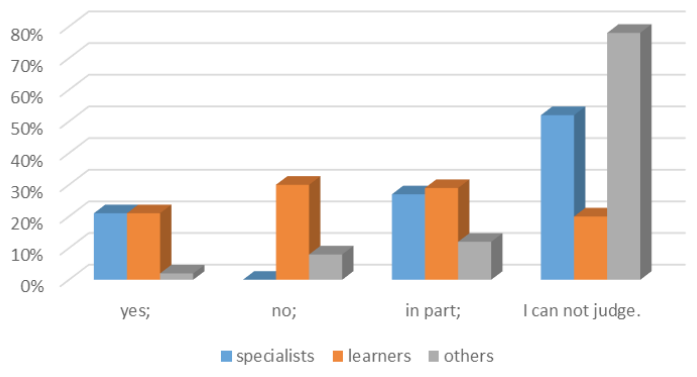

Fig. 6. Answer a question „Is there sufficient coordination between the departments that disclose the population in case of a radiation accident?"،

When examining in detail the main sites where nuclear facilities are or could be located, there is also a different degree of the suspected danger, the most serious being, according to all respondents from Turkey, where specialists give $37 \%$ and the other participants give 57 $64 \%$. The other possible answers are given in roughly the same range regardless of the type of category. It is quite clear that the Kozloduy NPP is the most reliable nuclear site in the region and is unlikely to have radioactive contamination (Figure 7).

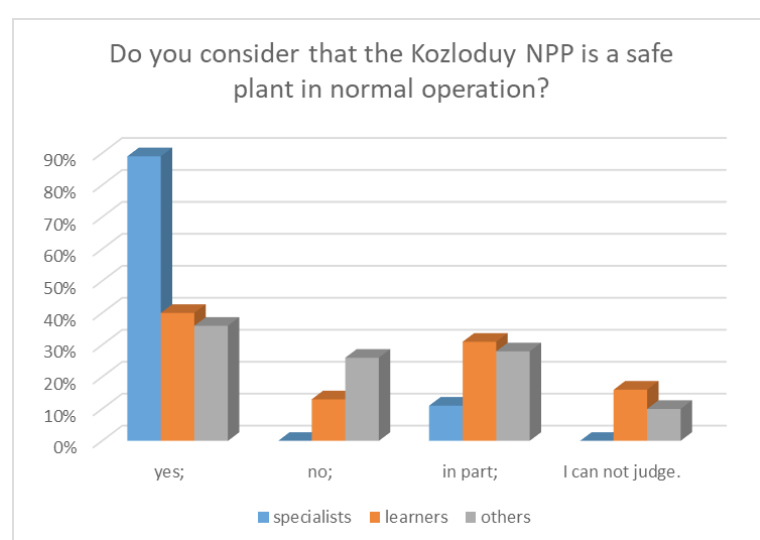

Fig. 7. Answer a question „Do you consider that the Kozloduy NPP is a safe plant in normal operation?"

When reading the survey data, it is clear that a large part can not judge whether the sites in Romania are potentially dangerous because of the lack of the necessary information. This leads us to the conclusion that a large part of the population in Bulgaria is not familiar with our neighbouring countries and we are not interested in enriching the knowledge about our safe living not only in terms of radiation safety but also in terms of other potential dangers and risks.
Although a referendum was recently held in Bulgaria on whether to develop nuclear power by building new capacities in the consultation, I included such a question. The predominant response was to Belene NPP, with approval of $80 \%$ for nuclear and safety specialists, while for the random respondents the positive response was $54 \%$. Accordingly, the disapproval was highest in the last category $-46 \%$, and in the experts it was only $20 \%$. With a ready-made one and almost ready-made second reactor, it is most reasonable to install them on the approved site and put into operation and Bulgaria to regain its dominant position in the energy exporter region, otherwise, in the near future, we may become extremely energetic dependent.

8. The majority of respondents from the second and third groups did not make suggestions, but there are also very reasonable and reasoned ones. Together with the suggestions of the employees in this field, we can bring them to the following summarized suggestions:

- The need of more quality annual exercises of all responsible institutions;

- Improving interaction between follow-up and disclosure organizations;

- Conducting seminars and refreshing effective staff training;

- To have up-to-date and accessible information on the radiation situation by explaining to the competent authorities and the media where and how the population will receive it;

- In the current development of the technique, the publicity should include, in addition to national television and radio and other electronic media and mobile operators, this being legislatively regulated;

- Increase the control points for monitoring the radiation background, taking into account the research and analysis [11].

\section{Conclusions}

1. The data from NASCRPF are used by the competent state authorities for preventive measures and for the organization of measures aimed at limiting the impact on human and the environment of radioactive particles, rays and isotopes;

2. The lowest radioactive background in Veliko Tarnovo is the lowest.

3. The awareness of both professionals and voluntary formations and the population itself is low, as shown by the survey data;

4. It is necessary to carry out an explanatory work among the population in order to improve its awareness. It is also necessary to carry out exercises for changing the radioactive situation.

5. The radiation gamma background of the neighbouring atmospheric layer is within the boundary of the country's background values without significant deviations over the last 20 years. Surface water currents and basins are in good radiological state and are controlled by the control bodies of the EEA in accordance with the applicable regulations. As far as the radiation status of the soils is concerned, no values 
are found above the backgrounds of the periodic and extraordinary measurements made during the last 15 years;

6. A clear program has been developed and implemented in terms of nuclear safety with the participation of all levels of state and local government [9]. A National Strategy for the Safe Management of Spent Nuclear Fuel and Radioactive Waste has been developed and the necessary control has been introduced on these activities. It is a weakness that changes the position of the bodies involved in this activity, there is an outflow of specialists and the thread between the state and municipal authorities and the voluntary organizations is broken.

7. Government documents were adopted to solve the problems with the consequences of priority liquidated sites of uranium mining and uranium processing. There are still weaknesses and under-reclaimed sites and unsealed former mines where environmental pollution from leakages and soils containing uranium and other radioactive isotopes may occur.

8. Research shows that specialists responsible for radiation protection at secondary and lower levels are not sufficiently theoretically and practically prepared and the exercises conducted are not effective. It is necessary for these specialists to undergo refresher courses every year for both radiation and accidents and other accidents. This would help to increase their knowledge, skills and competencies. The management of NASCRGF is carried out professionally, according to the requirements of the international organizations and according to the domestic and international legislation. An extension is needed from the team of specialists working to monitor the radiation background in Bulgaria, as well as improving their financial and resource security [8].

\section{REFERENCES}

[1] Annual Report NRA,the Council of Ministers, Sofia, 2015;

[2] Commission Regulation (Euratom) No 302/2005 of 8 February 2005 on the application of Euratom safeguards - Council/Commission statement, OJ L 054 28.02.2005 p. 1;

[3] Commission Regulation (EC) No 1609/2000 of 24 July 2000 establishing a list of products excluded from the application of Council Regulation (EEC) No 737/90 on the conditions governing imports of agricultural products originating in third countries following the accident at the Chernobyl nuclear power station, OJ L 185 25.07.2000 p. 27;

[4] Communication from the commission to the council and the european parliament. Communication on nuclear non-proliferation, Brussels, 26.3.2009;

[5] Dolchinkov N. , Investigation of the State of the Radiation Control Systems and the Actions of the Competent Authorities and the Population in the Event of a Change in the Radiation Background in Bulgaria, International conference KNOWLEDGE-BASED ORGANIZATION Subuy, Romania 24(3): p.38-44

[6] Dolchinkov N. and N. Nichev, Structure and Management of the National Automated System for Permanent Control of the Radiation Gamma Background in Bulgaria, De gruyter open, Land Forces Academy Review Vol. XXII, No 2(86), 2017, Sibiu, Romania, p 115-121.

[7] Dolchinkov N. , Historical overview and analysis of national automated system for continuous monitoring of gamma radiation, VIII науково-практичного семінару 3 міжнародною участю “Економічна безпека держави і науково-технологічні аспекти iї забезпечення“, Київ, 21-22 жовтня 2016 року ISBN 978-9667166-38-0 p. 220.228

[8] Dolchinkov N., Optimization of the systems for monitoring and public disclosure of radioactive contamination of the environment in Bulgaria, dissertation for acquisition of NSA Doctor, Veliko Tarnovo, NMU, 2017. Available: https:// http://nvu.bg/node/1895

[9] Dolchinkov N., Modernization of monitoring and public notification systems in case of radioactive pollution of the environment in Bulgaria, Scientific and Practical Journal "Global Nuclear Safety”, No. 3 (24) 2017, Moscow, MEPI, Russia, p 7-18. Available: https://www.researchgate.net/publication/321905753

[10] Dolchinkov N., Optimization of the systems for monitoring and public disclosure of radioactive contamination of the environment,International journal „, Knowledge “, Skopie ISSN 1857-92 Vol 15.1 p. 423-431 GIF 1.023 (2015). Available: https://www. researchgate.net/publication/320378173

Dolchinkov N., Analysis and Optimization of the National Automated System for Continuous Control of the Radiation Gamma Background, Third National Congress of Physical Sciences, Sofia, September 2016. ISBN 978-954-580-364-2 Available: https:// www.researchgate.net/publication/313109065 